\title{
DEVELOPMENT OF FAST-DISSOLVING TABLETS OF AMLODIPINE BESYLATE BY SOLID DISPERSION TECHNOLOGY USING POLOXAMER 407 AND POLOXAMER 188
}

\author{
MANIMARAN V, DAMODHARAN N* \\ Department of Pharmaceutics, SRM College of Pharmacy, SRM University, Kattangulathur - 603 203, Chennai, Tamil Nadu, India. \\ Email: damodharan.n@ktr.srmuniv.ac.in
}

Received: 13 February 2017, Revised and Accepted: 13 April 2017

\section{ABSTRACT}

Objective: Amlodipine besylate is a calcium channel blocker used in the treatment of hypertension which is practically insoluble in water. The present study aims to design oral fast-release tablets of amlodipine besylate and to optimize the dissolution of the drug by altering the carrier concentration.

Materials and Methods: Poloxamer 407 (P407) and poloxamer 188 (P188) were selected as carriers for the preparation of solid dispersion (SD) by the solvent evaporation method with different drug-polymer ratios. The prepared SDs were evaluated for the physical state, drug:carrier interactions by X-ray diffraction (XRD), infrared spectroscopy, differential scanning calorimetry, and scanning electron microscopy.

Results: From the dissolution studies, it is confirmed that all SDs showed increased dissolution rate when compared to pure amlodipine besylate. Among the two polymers used, P407 was found to be better than P188 in enhancing dissolution efficiency. The tablets were prepared using SD of amlodipine besylate containing P407 as a carrier. The results showed that P407 SD-based tablets gave a significantly higher release of amlodipine besylate when compared with control tablets. The infrared spectral studies showed that there was no significant interaction between amlodipine besylate and its formulation with different polymers used in the preparation of SDs. XRD studies revealed that the degree of crystallinity of amlodipine besylate reduced when the concentration of carriers increased, which reveals that the drug is in amorphous nature.

Conclusion: The combination of SD technology and using superdisintegrants in the formulation is a promising approach for preparing efficient, fastdissolving tablet of poorly water-soluble drugs, viz., amlodipine besylate.

Keywords: Amlodipine besylate, Calcium channel blocker, Fast-dissolving tablets, Poloxamer 407, Poloxamer 188, Solid dispersion, Superdisintergrants.

(C) 2017 The Authors. Published by Innovare Academic Sciences Pvt Ltd. This is an open access article under the CC BY license (http://creativecommons. org/licenses/by/4. 0/) DOI: http://dx.doi.org/10.22159/ajpcr.2017.v10i7.17686

\section{INTRODUCTION}

Drugs which come under the Class II of BCS system are characterized by high membrane permeability and slow dissolution. The poor aqueous solubility of the drug and their low dissolution rate in the gastrointestinal fluids often lead to insufficient bioavailability and are one of the most difficult problems in pharmaceutical technology. It is estimated that more than $35 \%$ of the known drugs and more than $25 \%$ of the newly discovered drugs possess such problems [1]. Solid dispersion (SD) technology can be used to enhance the dissolution rate of BCS Class II drugs, thereby improving their bioavailability. The enhancement of dissolution rate of the drug is important to attain suitable blood concentration for enhanced therapeutic effect as their dissolution rates are typically the rate-limiting step for bioavailability [2]. There are several methods employed for improving the solubility and dissolution rate of poorly aqueous soluble drugs, such as increasing the surface area by reducing the particle size, using surfactant systems, salt formation of the drug, prodrug approach, preparation of water-soluble complexes, and reducing the crystallinity of the drug. The most common method is decreasing the particle size by micronization technique. The technique is disadvantaged by the higher tendency of size reduced particles to stick together which leads to the formation of larger agglomerates which in turn leads to a decrease in effective surface area for dissolution. Nowadays, the most effective method to improve the dissolution rate is the use of SD technique [3]. The SDs are twocomponent systems consisting of a hydrophilic carrier in which the drug is incorporated. The SD technology gives the possibility to reduce the drug particle size almost to a molecular level and increased wettability [4]. In addition to this, the crystalline drug is transformed to amorphous form, which can be beneficial, since the dissolution of an amorphous drug does not require energy to break up the crystalline lattice [5].

Another method to improve the dissolution of SD tablet is by the addition of superdisintegrants because they do not irritate the gastrointestinal tract and can be used in low amounts in the formulations [6]. Cross croscarmellose sodium, crospovidone, and sodium starch glycolate were used as superdisintegrants [7].

Amlodipine besylate is a calcium channel blocker which may be utilized in the management of hypertension, and it belongs to BCS Class II category. One of the biggest problems with this drug is its low solubility in biological fluids, which results into poor bioavailability after oral administration. Hence, SD technique can be used to improve the dissolution rate of the drug. The drug works by slowing down the rate at which calcium moves into heart, blood vessel walls, allowing better blood flow. Poloxamer 407 (P407) and poloxamer 188 (P188) were used as the carriers for the preparation of SDs with amlodipine besylate [8]. Poloxamer is a synthetic block copolymer of ethylene oxide and propylene oxide and used widely in pharmaceutical preparations [9].

\section{MATERIALS AND METHODS}

Materials

Amlodipine besylate, P407, and P188 were obtained from Orchid Chemicals \& Pharmaceutics Ltd., Chennai. All other chemicals were of reagent grade and used without purification.

\section{Preparation of SDs}

Dichloromethane and ethanol were used as the solvent, and five different ratios of drug and carrier were used (1:1, 1:2, 1:3, 1:4, 1:5) 
for preparing SDs of amlodipine besylate. In solvent evaporation method, respective quantity of carrier was dissolved in required volume of dichloromethane and ethanol in a conical flask to get a clear completely soluble solution using a magnetic stirrer. The weighed amount of amlodipine besylate was added to this solution carefully with constant stirring. Stirring was continued until the drug is completely dissolved in the polymeric solution. Then, the solvent was eliminated by evaporation at $40^{\circ} \mathrm{C}$ under vacuum. The mass obtained was dried in a desiccator, and the dried mass was pulverized and sifted through mesh no. $60[10,11]$.

\section{Drug content uniformity of SDs}

The prepared SDs were tested for drug content uniformity. From each batch, the SDs equivalent to $20 \mathrm{mg}$ of amlodipine besylate was taken and analyzed for drug content uniformity [12]. An accurately weighed quantity of amlodipine besylate SDs were taken in a $100 \mathrm{ml}$ volumetric flask and dissolved in ethanol. The solutions were filtered, suitably diluted, and analyzed for drug content using a Shimadzu ultraviolet (UV)-visible spectrophotometer.

\section{Infrared spectral analysis}

Compatibility studies of amlodipine besylate and the polymers were carried out using Fourier transform infrared (FTIR) spectroscopy. FTIR spectra of the samples were obtained in the range of $4000-450 / \mathrm{cm}$ using a Perkin Elmer-FT-IR 8201 PC spectrophotometer by the KBr-disc method [13].

\section{Powdered X-ray diffraction (XRD) studies}

The powdered XRD patterns were recorded using X'Pert PRO-Analytical diffractometer with $\mathrm{Cu}$ as an anode material and operated at a voltage of $30 \mathrm{kV}$ and a current of $15 \mathrm{~mA}$. The samples were analyzed in $2 \mathrm{q}$ angle range of $0^{\circ}-100^{\circ}$ and the process parameters were set as follows - sampling width of $0.010^{\circ}(2 q)$ at a scanning speed of $1^{\circ} / \mathrm{min}$ and scan mode set is continuous [14]

\section{Differential scanning calorimetry (DSC)}

The DSC studies were carried out for pure drug and SDs using DSC60 (Shimadzu Corporation Japan) instrument. All standards were used to calibrate the DSC temperature, and the samples were sealed in aluminum pans and heated at a persistent rate of $5^{\circ} \mathrm{C} / \mathrm{min}$ over a temperature range of $25-225^{\circ} \mathrm{C}$. A static atmosphere was maintained by purging nitrogen gas at the flow rate of $50 \mathrm{ml} / \mathrm{min}$ [15].

\section{Scanning electron microscopy (SEM)}

The surface morphology of amlodipine besylate, P407, P188, and SDs was examined using SEM. The samples were mounted on a doublefaced adhesive tape and sputtered with thin gold palladium layer, and the surface morphology was analyzed with an SEM (Stereoscan 440, Leo Leica, Cambridge, UK) [16].

\section{Dissolution studies}

Dissolution studies of amlodipine besylate pure drug and SDs were performed according to the method prescribed in USP XXIV using apparatus 2. The paddle speed set at $50 \mathrm{rpm}$ in $900 \mathrm{ml}$ of phosphate buffer $\mathrm{pH} 6.8$ and the temperature maintained at $37^{\circ} \mathrm{C}$. SD powders equivalent to $10 \mathrm{mg}$ of amlodipine besylate were taken for dissolution. Aliquots of $5 \mathrm{ml}$ were withdrawn at selected time intervals $(10,20,30$,
40, 60 and 90 minutes), and the samples are replaced with the fresh dissolution medium which is pre-warmed to $37^{\circ} \mathrm{C}$. The quantity of drug released was estimated by measuring the absorbance at $239 \mathrm{~nm}$ by a UV spectroscopy nm [17-19].

\section{Preparation of fast-dissolving tablets}

The SD formulation which showed highest dissolution rate was formulated into tablets using various proportions of croscarmellose sodium, sodium starch glycolate, sodium, and crospovidone as superdisintegrants. The SDs equivalent to $10 \mathrm{mg}$ of amlodipine besylate was taken, and the formulation of the prepared tablet is given in Table 1. The drug or its equivalent SDs was mixed with the excipients for 15 minutes by bottle method, before compression into tablets [20]. The tablet preparation process employed Cadmach 16 station rotary tablet making machine, and the compression force was adjusted for preparing the tablets having a hardness of 4-5 Kp.

\section{Evaluation of fast-dissolving tablets}

\section{Uniformity of weight}

Twenty tablets were weighed individually, and the average weight is compared with the individual tablet weights. As per the USP specifications, for tablets weighing $200 \mathrm{mg}$, the allowed weight variation deviation is $7.5 \%$. The tablets meet the USP test if not more than two tablets are outside the limit and no tablet differs by more than twice the limit [21].

\section{Tablet friability}

The friability of the tablets was measured in Roche friabilator. 20 tablets were selected randomly, weighed and placed in friability apparatus, and subjected to $25 \mathrm{rpm}$ for 4 minutes (100 revolutions). The tablets were wiped with a clean cloth and weighed again. The friability was calculated as the percentage loss should not exceed 1\% [22].

\section{Drug content}

The drug content was determined by randomly selecting 30 tablets, and from these, ten tablets were individually assayed for drug content determination. The tablets were acceptable if the drug content of each of at least nine tablets were in the range of $85-115 \%$ of the stated amount of the drug. The $10^{\text {th }}$ tablet should not contain $<75 \%$ or $>125 \%$ of the labeled content. If these conditions were not met, remaining 20 tablets must be analyzed individually and all they should be within the limit [23].

\section{RESULTS AND DISCUSSION}

\section{Drug content}

The amlodipine besylate SDs were tested for drug content by UV method, and the drug content was found to be $97.5 \pm 3 \% \mathrm{w} / \mathrm{w}$. All the SDs were uniform in drug content, and the results are shown in Table 2.

\section{Infrared spectral analysis}

The IR spectra of P407, P188, amlodipine besylate, and SDs are shown in Figs. 1 and 2. The spectrum of the pure drug shows strong absorption band at $3298.79 / \mathrm{cm}$ due to the stretching of the N-H group. The band at $3156.11 / \mathrm{cm}$ can be due to the stretching of aromatic C-H stretching. The strong absorption band at $2984.45 / \mathrm{cm}$ can be attributed to the

Table 1: Master formula for the preparation of amlodipine besylate tablets

\begin{tabular}{|c|c|c|c|c|c|c|c|c|c|c|}
\hline S. No. & Ingredients & F1 & F2 & F3 & F4 & F5 & F6 & F7 & F8 & F9 \\
\hline 1 & Amlodipine besylate P 407 1:5 Solid dispersion & 60 & 60 & 60 & 60 & 60 & 60 & 60 & 60 & 60 \\
\hline 2 & Crospovidone & 4 & 6 & 8 & - & - & - & - & - & - \\
\hline 3 & Croscarmellose sodium & - & - & - & 8 & 10 & 12 & - & - & - \\
\hline 4 & Sodium starch glycolate & - & - & - & - & - & - & 8 & 10 & 12 \\
\hline 5 & Magnesium stearate & 2 & 2 & 2 & 2 & 2 & 2 & 2 & 2 & 2 \\
\hline 6 & Aerosil & 2 & 2 & 2 & 2 & 2 & 2 & 2 & 2 & 2 \\
\hline 7 & Microcrystalline cellulose & 132 & 130 & 128 & 128 & 126 & 124 & 128 & 126 & 124 \\
\hline
\end{tabular}


C-H stretching. The band at $1677.44 / \mathrm{cm}$ is for $\mathrm{C}=0$ bond and the band at $1493.94 / \mathrm{cm}$ is for the aromatic $\mathrm{C}=\mathrm{C}$ bond. The strong absorption band at $1302.68 / \mathrm{cm}$ is due to $\mathrm{C}-\mathrm{N}$. The bands at $1205.85,1122.19$, and 1095.52 are due to C-0. The spectrum of pure P407 and P188 shown in Figs. 1 and 2 was in good agreement with published data on the polymer. IR spectra of amlodipine besylate and its SDs are identical. The principle IR absorption peaks of amlodipine besylate SDs were observed and found to be identical with the spectra of amlodipine besylate pure drug. Thus, from the spectra, it was understood that there was no significant interaction between amlodipine besylate and the polymers used in the preparation of SDs.

\section{Powdered XRD studies}

The XRD measurements were conducted to clarify the physicochemical characteristics of all SDs. The XRD pattern of pure amlodipine besylate exhibited sharp, highly intense, and less diffused peaks indicating the crystalline nature of the pure drug. It showed sharp diffraction peaks at $2 \theta$ degree equal to $3.532,10.214,12.860,14.293,21.731,24.030$, 26.618 , and 31.829. The XRD of SDs showed a reduction in diffraction peak intensity at $2 \theta$ values at $2.320,13.864,14.391,20.581,25.283$, and 29.436 indicating that the significant reduction in crystallinity of amlodipine besylate (Fig. 3).

DSC

The DSC analysis was done for pure amlodipine besylate and SDs of amlodipine besylate with carriers P407 and P188 which showed higher saturation solubility of the pure drug than the polymers

Table 2: Drug content uniformity of solid dispersions of amlodipine besylate

\begin{tabular}{lll}
\hline S. No. & Solid dispersions(drug:carrier) & \% Drug content \\
\hline 1 & P407 1:1 & $95.9 \pm 0.69$ \\
2 & P407 1:2 & $97.6 \pm 0.24$ \\
3 & P407 1:3 & $98.3 \pm 0.47$ \\
4 & P407 1:4 & $99.2 \pm 0.58$ \\
5 & P407 1:5 & $96.8 \pm 0.94$ \\
6 & P188 1:1 & $95.6 \pm 0.30$ \\
7 & P188 1:2 & $97.9 \pm 0.51$ \\
8 & P188 1:3 & $99.1 \pm 0.18$ \\
9 & P188 1:4 & $96.5 \pm 0.72$ \\
10 & P188 1:5 & $98.8 \pm 0.32$ \\
\hline
\end{tabular}

P188: Poloxamer 188, P407: Poloxamer 407 used. The DSC thermogram of pure amlodipine besylate (Fig. 4a) showed a sharp endothermic peak which was ascribed to drug melting indicating its crystalline nature. The DSC curve of P407 (Fig. 4b) and P188 (Fig. 4c) showed a sharp endothermic peak at $58.9^{\circ} \mathrm{C}$ and $55.5^{\circ} \mathrm{C}$ corresponding to the melting point of $\mathrm{P} 407$ and P188. The endothermic peak corresponding to drug melting was shifted toward lower temperature in SDs. This could be attributed to higher polymer concentration and uniform distribution of the drug in polymer.

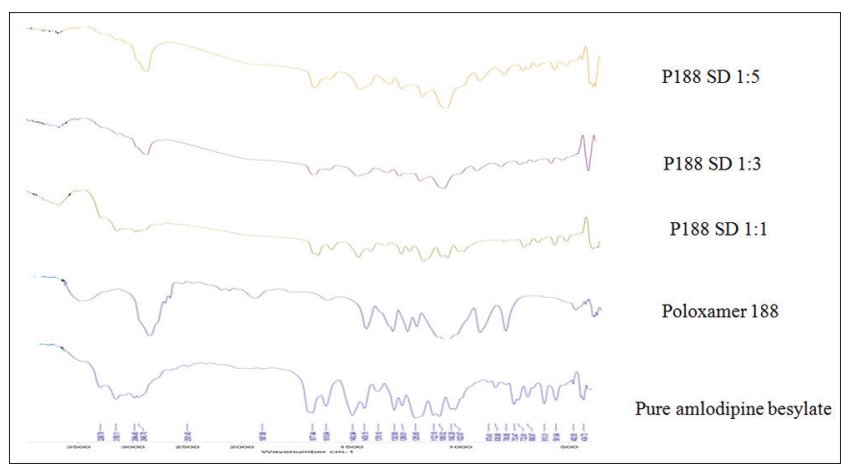

Fig. 1: Fourier transform infrared spectra of amlodipine besylate, poloxamer 188, and their solid dispersions

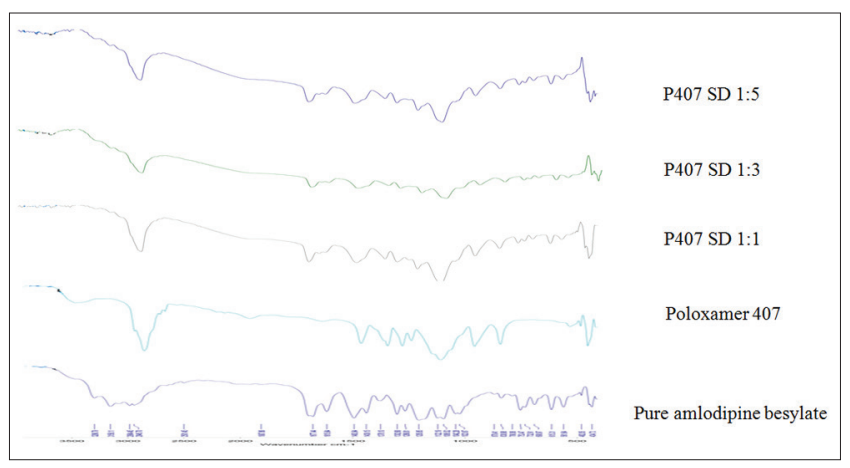

Fig. 2: Fourier transform infrared spectra of amlodipine besylate, poloxamer 407, and their solid dispersions

Table 3: Dissolution profile of amlodipine besylate from P407 SD at different drug: carrier ratios

\begin{tabular}{|c|c|c|c|c|c|c|}
\hline \multirow{2}{*}{$\begin{array}{l}\text { Time in } \\
\text { minutes }\end{array}$} & \multicolumn{6}{|c|}{ Percentage amlodipine besylate released from P407 SDs } \\
\hline & Pure amlodipine besylate & 1:1 & $1: 2$ & $1: 3$ & $1: 4$ & 1:5 \\
\hline 10 & 6.38 & 43.54 & 47.49 & 53.64 & 55.49 & 63.35 \\
\hline 20 & 8.97 & 49.28 & 50.25 & 55.71 & 68.43 & 77.85 \\
\hline 30 & 15.82 & 56.81 & 53.32 & 63.46 & 71.53 & 85.56 \\
\hline 40 & 18.39 & 63.35 & 68.20 & 74.91 & 86.2 & 98.31 \\
\hline 60 & 22.74 & 75.89 & 79.59 & 85.27 & 93.57 & 100 \\
\hline 90 & 26.54 & 81.34 & 88.27 & 93.94 & 100 & 100 \\
\hline
\end{tabular}

SD: Solid dispersion, P407: Poloxamer 407

Table 4: Dissolution profile of amlodipine besylate from P188 SD at different drug:carrier ratios

\begin{tabular}{|c|c|c|c|c|c|c|}
\hline \multirow{2}{*}{$\begin{array}{l}\text { Time in } \\
\text { minutes }\end{array}$} & \multicolumn{6}{|c|}{ Percentage amlodipine besylate dissolved from P188 solid dispersions } \\
\hline & Pure amlodipine besylate & $1: 1$ & $1: 2$ & $1: 3$ & 1:4 & $1: 5$ \\
\hline 10 & 6.38 & 38.54 & 41.45 & 48.67 & 51.31 & 58.26 \\
\hline 20 & 8.97 & 42.93 & 48.29 & 58.74 & 64.38 & 69.57 \\
\hline 30 & 15.82 & 51.08 & 56.84 & 61.95 & 69.55 & 75.38 \\
\hline 40 & 18.39 & 56.89 & 64.69 & 68.29 & 77.79 & 82.11 \\
\hline 60 & 22.74 & 61.05 & 69.28 & 76.15 & 81.22 & 85.59 \\
\hline 90 & 26.54 & 68.70 & 76.75 & 83.27 & 88.19 & 91.25 \\
\hline
\end{tabular}

SD: Solid dispersion, P188: Poloxamer 188 


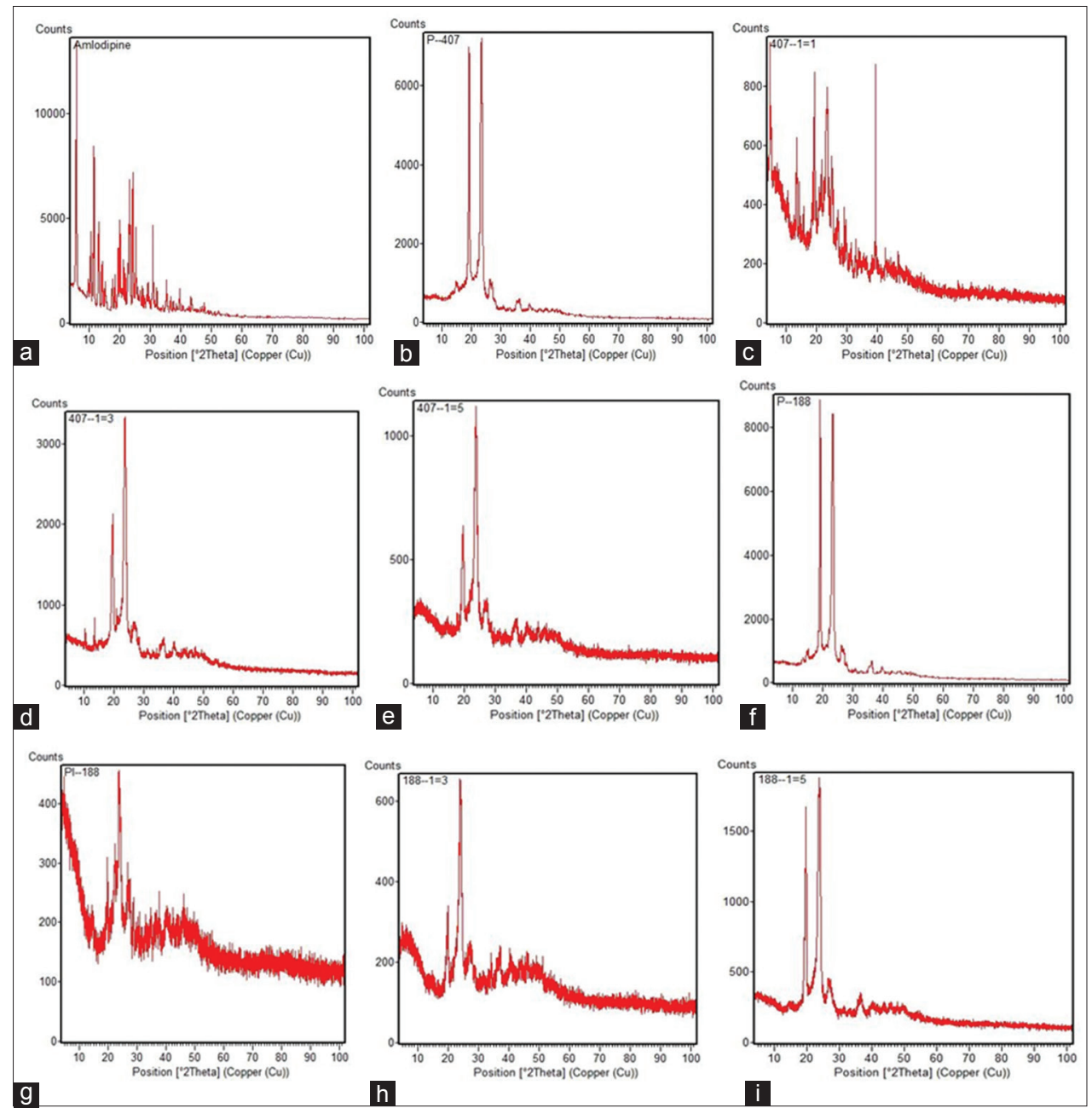

Fig. 3: X-ray diffraction diffractogram of (a) pure amlodipine besylate, (b) poloxamer 407 (P407), (c) amlodipine besylate $\mathrm{P407}$ solid dispersion (SD) 1:1, (d) amlodipine besylate P407 SD 1:3, (e) amlodipine besylate P407 SD 1:5, (f) poloxamer 188 (P188), (g) amlodipine besylate P188 SD 1:1, (h) amlodipine besylate P407 SD 1:3, (i) amlodipine besylate P407 SD 1:5

Table 5: Dissolution profiles of fast-dissolving tablets

\begin{tabular}{|c|c|c|c|c|c|c|c|c|c|c|}
\hline \multirow{2}{*}{$\begin{array}{l}\text { Time in } \\
\text { minutes }\end{array}$} & \multicolumn{10}{|c|}{ Cumulative percentage drug released } \\
\hline & Control tablet & F1 & F2 & F3 & F4 & F5 & F6 & F7 & F8 & F9 \\
\hline 10 & 6.42 & 47.63 & 53.84 & 61.85 & 46.96 & 49.47 & 55.75 & 41.93 & 43.87 & 50.25 \\
\hline 20 & 9.35 & 56.71 & 61.63 & 69.43 & 56.84 & 55.58 & 61.39 & 48.56 & 50.84 & 59.01 \\
\hline 30 & 11.78 & 65.50 & 69.21 & 76.80 & 59.82 & 67.83 & 73.23 & 56.07 & 58.38 & 68.82 \\
\hline 40 & 16.25 & 72.54 & 74.90 & 83.47 & 65.37 & 71.95 & 79.64 & 68.18 & 69.82 & 74.91 \\
\hline 60 & 18.86 & 81.07 & 83.97 & 91.05 & 73.08 & 79.48 & 87.42 & 74.95 & 78.04 & 82.73 \\
\hline 90 & 31.71 & 88.68 & 93.28 & 98.71 & 81.37 & 85.06 & 92.62 & 79.91 & 87.32 & 90.84 \\
\hline
\end{tabular}

\section{SEM}

The SEM analysis of pure drug in Fig. 5a showed crystalline in nature, and the drug particles were irregular in shape. The SDs of amlodipine besylate with P407 and P188 (Fig. 5b-e) showed a homogeneous dispersion indicating that the amlodipine besylate is dispersed uniformly in carrier matrices of SDs, assuming amorphous SD state $[24,25]$.

\section{Dissolution studies of SDs}

For poorly water-soluble drugs, especially BCS Class II drugs, the improvement of drug solubility sometimes results in the enhancement of oral bioavailability [26-28]. The dissolution tests on pure amlodipine besylate and its SDs were carried out up to 90 minutes in phosphate buffer pH 6.8. Figs. 6 and 7 show the dissolution profile of pure drug powder and SDs with different carriers. The dissolution profile of pure drug shows slow dissolution rate with only $6.42 \%$ of the drug released in first 10 minutes. The total amount of drug released in 90 minutes was found to be $31.71 \%$ which revealed its high lipophilicity and its crystallinity (Table 3). Preparation of SD of the drug with P407 resulted in a significant increase in the dissolution rate compared to the pure drug. The enhancement of dissolution depended on the concentration of polymer in the SD [29-31]. Hence, the quantity of drug released in the first 10 min was increased gradually with increase in carrier concentration to reach $100 \%$ at $1: 4$ (drug to polymer ratio) which is much higher than that of pure amlodipine besylate or SDs containing lower proportions of P407.

For P188, preparation of SD with the drug resulted in gradual increase in the dissolution rate at low carrier concentration so that the amount of drug dissolved in the first 10 min was $38.54 \%$ in case of 1:1 (drug to 


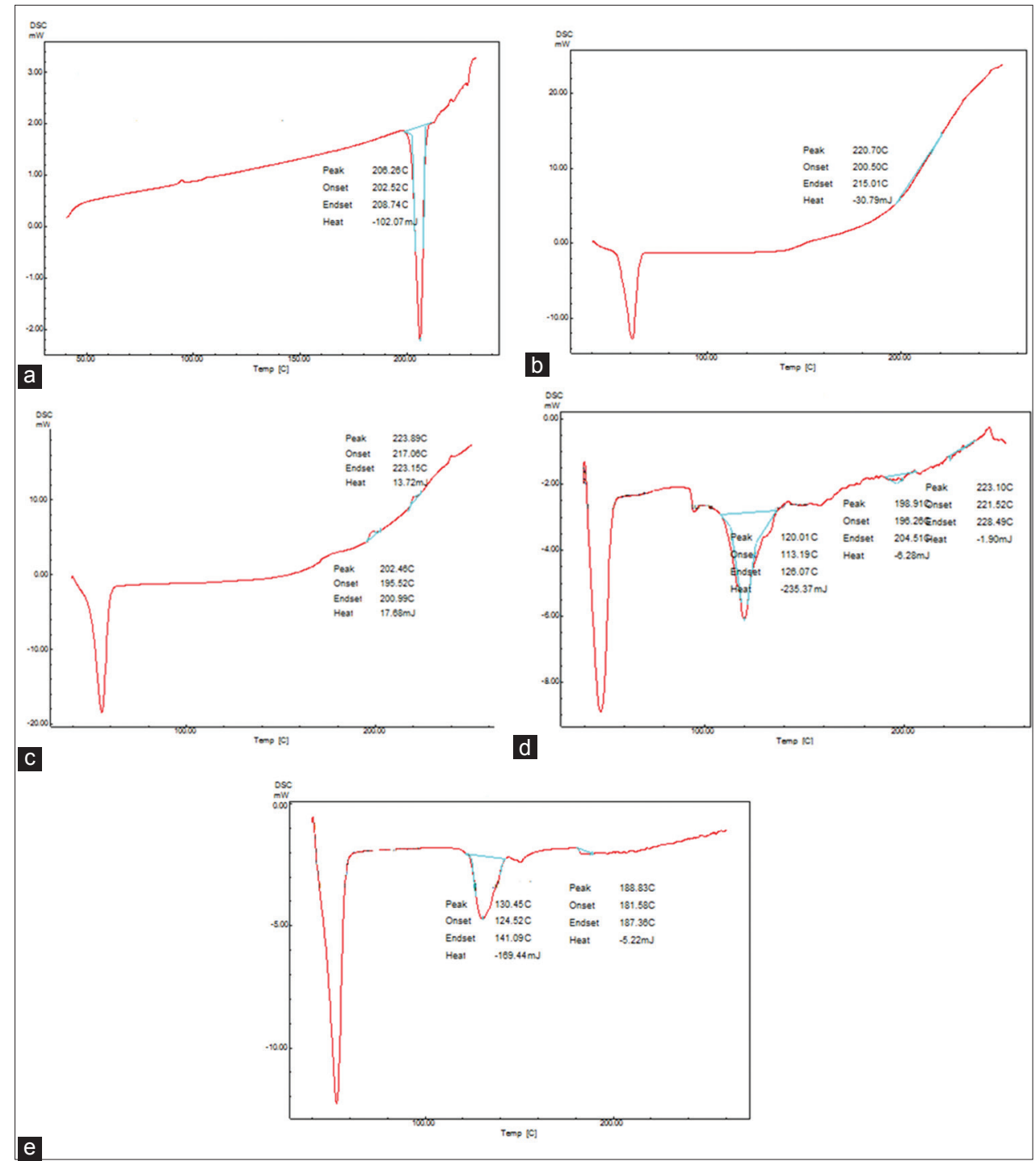

Fig. 4: Differential scanning calorimetry curve of (a) pure amlodipine besylate, (b) poloxamer 407 (P407), (c) poloxamer 188 (P188), (d) amlodipine besylate P188 solid dispersion (SD) 1:5 (e) amlodipine besylate P407 SD 1:5

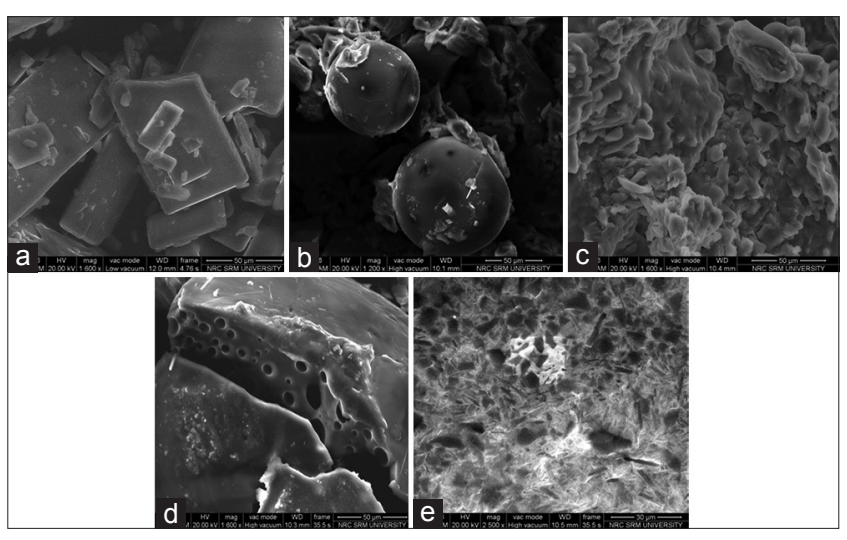

Fig. 5: Scanning electron microscopy microphotograph of (a) pure drug amlodipine besylate, (b) poloxamer 407 (P407) polymer, (c) amlodipine besylate $\mathrm{P} 407$ solid dispersion (SD) 1:5, (d) poloxamer 188 (P188) polymer, (e) amlodipine besylate P188 SD 1:5

polymer ratios). This amount increased significantly increased in the case of $1: 2,1: 3,1: 4$ and reached $91.25 \%$ of the labeled amount in $1: 5$

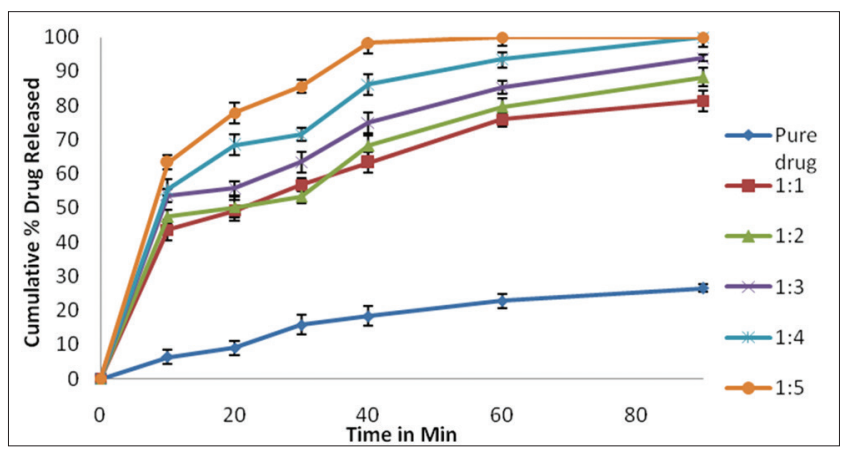

Fig. 6: Dissolution profile of amlodipine besylate from poloxamer 407 solid dispersion at different drug:carrier ratios

ratio (Table 4). This result shows the need for higher concentrations of the polymer to convert it into amorphous form and to achieve better dissolution parameters.

\section{Characterization of tablets}

The formulated tablets were found to be uniform in weight, and the weight variation was within the limit of $7.5 \%$. It was found that the 


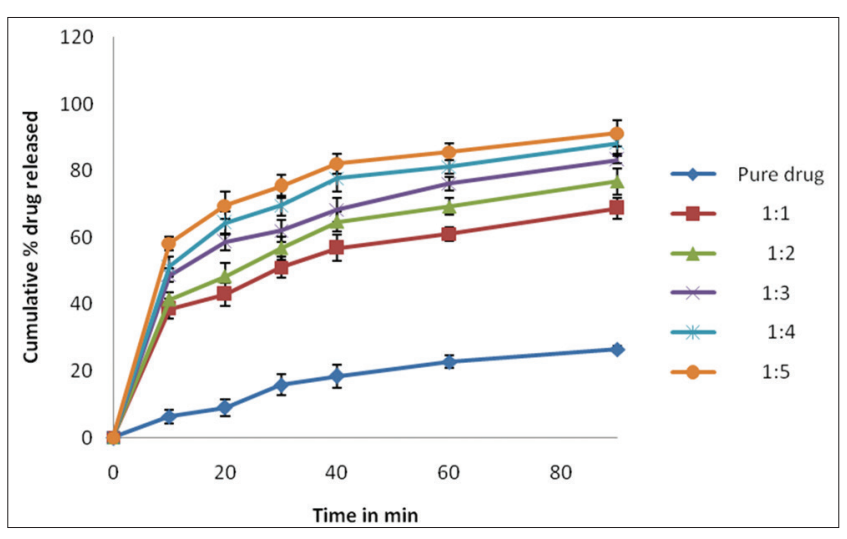

Fig. 7: Dissolution profile of amlodipine besylate from poloxamer 188 solid dispersion at different drug:carrier ratios

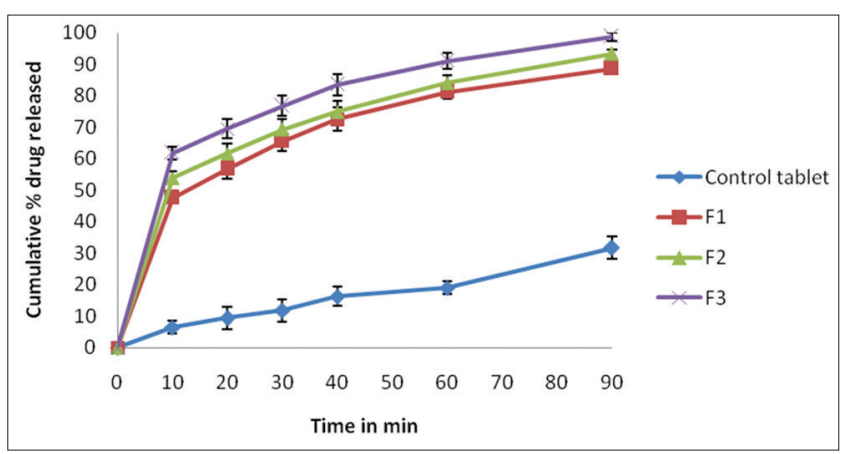

Fig. 8: Dissolution profiles of control tablet and tablets containing solid dispersion with crospovidone as superdisintegrant

friability of all tablet formulations was $<1 \%$. The result shows resistant to loss of weight indicates the tablet ability to withstand abrasion in handling, packaging, and shipment. The hardness of tablet ranged from 3.5 to $4 \mathrm{~kg} / \mathrm{cm}^{2}$. The percent drug content was found to be $100 \pm 5 \%$.

\section{In vitro study of tablets}

The results reveal that the disintegration time of the tablets decreased with increase in the amount of superdisintegrants used in the tablet formulation. It shows that increase in the level of superdisintegrants (croscarmellose sodium, sodium starch glycolate, and crospovidone) had a positive effect on the disintegration time of fast-superdissolving tablets.

The dissolution behavior of various formulations and the control tablets is depicted in Figs. 8-10. The drug release from the tablet formulations followed the order: $\mathrm{F} 3>\mathrm{F} 2>\mathrm{F} 6>\mathrm{F} 9>\mathrm{F} 1>\mathrm{F} 8>\mathrm{F} 5>\mathrm{F} 4>\mathrm{F} 7$. The pattern gives an idea about the effect of superdisintegrants in drug-release profile of fast-dissolving tablets (Table 5). The in vitro drug dissolution profile of fast dissolving tablets was found to be increased with increase in superdisintegrant level. The highest drug release was observed in crospovidone followed by croscarmellose sodium and sodium starch glycolate. The fast-dissolving tablets containing crospovidone (4\%) showed the highest drug release $(98.71 \%)$. The control tablets were prepared with crospovidone (4\%) with other ingredients using pure amlodipine besylate, and the dissolution profile is compared with the formulation containing SD of drug (Figs. 8-10).

\section{CONCLUSION}

In the present study, the SDs of amlodipine besylate were prepared with P188 and P407 with the aim of enhanced dissolution rate. The fastest drug release was obtained from amlodipine besylate P407 SD in the ratio of 1:5 prepared by solvent evaporation method. The preparation of fast-dissolving tablets using the SD of amlodipine besylate is a unique

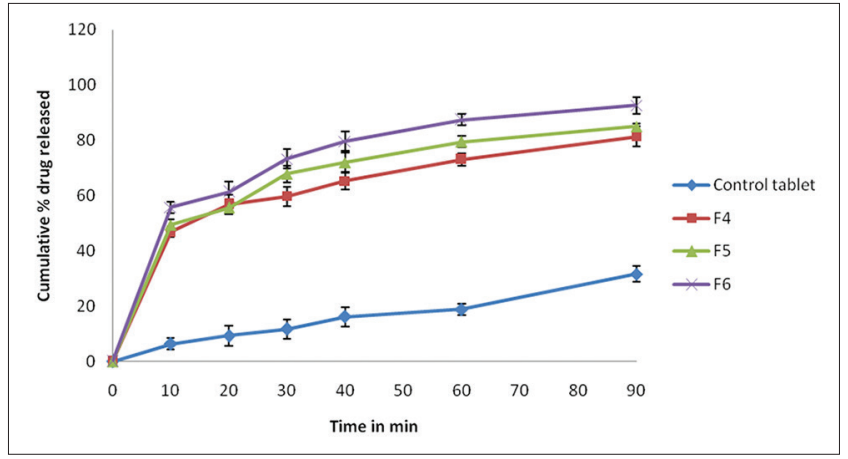

Fig. 9: Dissolution profiles of control tablet and tablets containing solid dispersion with croscarmellose sodium as superdisintegrant

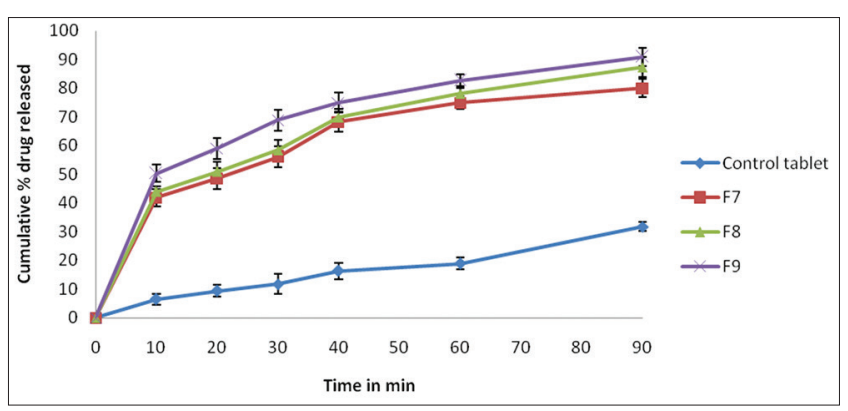

Fig. 10: Dissolution profiles of control tablet and tablets containing solid dispersion with sodium starch glycolate as superdisintegrant

technique by which the dissolution rate of the drug can be increased which is the most challenging aspect of drug delivery. The method employed was found to be economical and industrially feasible. Thus, it can be concluded that combination of SD and superdisintegrants in the formulation is a promising approach for preparing efficient, fast dissolving tablet of poorly water-soluble drugs, viz., amlodipine besylate.

\section{ACKNOWLEDGMENT}

We are thankful to SRM College of Pharmacy, SRM University, Kattankulathur, for their support and encouragement in carrying out this research work.

\section{REFERENCES}

1. Gibaldi M. Biopharmaceutics and Clinical Pharmacokinetics. $4^{\text {th }}$ ed. Philadelphia, PA: Lea \& Febiger; 1991.

2. Nadia S, Riaz U, Naz H, Kumar B. Enhancement of oral bioavailability and solid dispersion: A review. J Appl Pharm Sci 2011;1(7):13-20.

3. Leuner C, Dressman J. Improving drug solubility for oral delivery using solid dispersions. Eur J Pharm Biopharm 2000;50(1):47-60.

4. Srinarong P, Faber JH, Visser MR, Hinrichs WL, Frijlink HW. Strongly enhanced dissolution rate of fenofibrate solid dispersion tablets by incorporation of superdisintegrants. Eur J Pharm Biopharm 2009;73(1):154-61.

5. Kim EJ, Chun MK, Jang JS, Lee IH, Lee KR, Choi HK. Preparation of a solid dispersion of felodipine using a solvent wetting method. Eur $\mathbf{J}$ Pharm Biopharm 2006;64(2):200-5.

6. Dhirendra K, Lewis S, Udupa N, Atin K. Solid dispersions: A review. Pak J Pharm Sci 2009;22(2):234-46.

7. Shah PP, Mashru RC. Development and evaluation of artemether taste masked rapid disintegrating tablets with improved dissolution using solid dispersion technique. AAPS PharmSciTech 2008;9(2):494-500.

8. Newa M, Bhandari KH, Oh DH, Kim YR, Sung JH, Kim JO, et al. Enhanced dissolution of ibuprofen using solid dispersion with poloxamer 407. Arch Pharm Res 2008;31(11):1497-507.

9. Newa M, Bhandari KH, Li DX, Kwon TH, Kim JA, Yoo BK, 
et al. Preparation, characterization and in vivo evaluation of ibuprofen binary solid dispersions with poloxamer 188. Int J Pharm 2007;343(1-2):228-37.

10. Sethia S, Squillante E. Solid dispersion of carbamazepine in PVP K30 by conventional solvent evaporation and supercritical methods. Int J Pharm 2004;272(1-2):1-10.

11. Nirav P, Jayavadan P. Dissolution enhancement of anti depressant escitalopram oxalate by solid dispersion technique. J Curr Pharm Res 2012;9(1):26-32

12. Ruchi T, Gaurav T, Birendra S, Awani R. Solid dispersions: An overview to modify to modify bioavailability of poorly water soluble drugs. Int $\mathrm{J}$ Pharmtech Res 2009;1(4):1338-49.

13. Gupta MM, Patel MG, Patel NS, Kedawat M. Enhancement of dissolution rate of ibuprofen by preparing solid dispersion using different methods. Int J Pharm Pharm Sci 2011;3(3):204-6.

14. Sivakranth M, Altaf AS, Rajasekhar S. Formulation and evaluation of oral fast dissolving tablets of sildinafil citrate. Int J Pharm Pharm Sci 2011;3(2):112-21

15. Lalitha Y, Lakshmi PK. Enhancement of dissolution of nifedipine by surface solid dispersion technique. Int $\mathrm{J}$ Pharm Pharm Sci 2011;3(3):41-6.

16. Janssens S, Van den Mooter G. Review: Physical chemistry of solid dispersions. J Pharm Pharmacol 2009;61(12):1571-86.

17. Kerc J, Mohar M, Sric S, Kofler B, Smid-Korbar J. Dissolution study of felodipine solid dispersions. Acta Pharm Zagrebu 1993;43(2):113-20.

18. Doherty C, York P. Mechanisms of dissolution of frusemide/PVP solid dispersions. Int J Pharm 1987;34(3):197-5.

19. Craig DQ, Newton JM. The dissolution of nortriptyline HCL from polyethylene glycol solid dispersions. Int J Pharm 1992;78(1-3):175-82.

20. Kranthikumar M, Lakshmi PK, Giriprasad VS. Development and evaluation of solid dispersion formulated ibuprofen tablets using cyclodextrins as carrier. Int J Pharm Res Dev 2012;3(11):93-101.

21. Deshmuk KR, Sunil KJ. Development of aceclofenac mouth dissolving tablets using solid dispersion technique: In-vitro evaluation. Indian J Pharm Educ Res 2012;46(2):97-104.
22. Jain CP, Naruka PS. Formulation and evaluation of fast dissolving tablets of valsartan. Int J Pharm Pharm Sci 2009;1(1):219-26.

23. Vijayakumar V, Gunasekharan V, Padmini BS, Kumar JM, Mounica R. Formulation and evaluation of levozcetrizine dihydrochloride fast dissolving tablets using super disintegrants. Int J Pharm Pharm Sci 2013;5(4):324-8

24. Patil S, Kuchekar B, Chabukswar A, Jagdale S. Formulation and evaluation of extended-release solid dispersion of metformin hydrochloride. J Young Pharm 2010;2(2):121-9.

25. Poovi S, Rajpriyadarsini S, Uma S, Vinothini R. Development, characterization and solubility enhancement of comparative dissolution study of second generation of solid dispersions and microspheres for poorly water soluble drug. Asian J Pharm Sci 2015;10(5):433-41.

26. Onoue S, Sato H, Ogawa K, Kawabata Y, Mizumoto T, Yuminoki K, et al. Improved dissolution and pharmacokinetic behavior of cyclosporine A using high-energy amorphous solid dispersion approach. Int J Pharm 2010;399(1-2):94-101.

27. Bley H, Fussnegger B, Bodmeier R. Characterization and stability of solid dispersions based on PEG/polymer blends. Int $\mathrm{J}$ Pharm 2010;390(2):165-73.

28. Xingwang Z, Ningyun S, Baojian W, Yi L, Tianzheng G, Wei W. Physical characterization of lansoprazole/PVP solid dispersion prepared by fluid-bed coating technique. Powder Technol 2008;182(3):480-5.

29. Veerendra R, Pankaj R, Surender G, Harish D, Gitika A, Manju N. Formulation and characterization of solid dispersion of glimepride through factorial design. Iran J Pharm Sci 2011;7(1):7-16.

30. Gamal M, Maghraby EI, Ramy E. Fast disintegrating tablets of nisoldipine for intra oral administration. Pharm Dev Technol 2014;19(6):641-50.

31. Jun SW, Kim MS, Kim JS, Park HJ, Lee S, Woo JS, et al. Preparation and characterization of simvastatin/hydroxypropyl-beta-cyclodextrin inclusion complex using supercritical antisolvent (SAS) process. Eur J Pharm Biopharm 2007;66(3):413-21. 